\section{Should We Continue to Use Stress Ulcer Prophylaxis for Critically III Patients?}

\section{THE "PRO" SIDE}

When patients are critically ill, they are at risk of stress-related gastrointestinal mucosal damage, commonly referred to as stress ulcers. Within 24 hours of admission to an intensive care unit (ICU), there may be endoscopic evidence of gastritis, which eventually progresses to mucosal erosions and potentially ulceration and hemorrhage. ${ }^{1}$ The formation of these lesions is thought to be related to a reduction in splanchnic mucosal blood flow, as a result of the abnormally high physiologic stress seen in critical illness. Clinically significant bleeding from stress ulcers has been associated with increases in both morbidity and mortality. ${ }^{2}$ As such, prophylaxis against stress ulcers, with various gastric protective or acid-suppressive therapies, has been standard practice in critical care units for more than 40 years. ${ }^{1,3}$

In their large, prospective, randomized controlled trial, published in 1998, Cook and others ${ }^{4}$ reported that the incidence of clinically important gastrointestinal bleeding was lower with ranitidine than with sucralfate (1.7\% versus $3.8 \%)$. On the basis of this landmark trial, histamine-2 receptor antagonists (H2RAs) became the gold standard for stress ulcer prophylaxis. With the subsequent introduction of proton pump inhibitors (PPIs) came small trials comparing the efficacy of these newer and more potent agents with that of the H2RAs. Several meta-analyses have suggested increased efficacy with PPIs relative to H2RAs for stress ulcer prophylaxis, ${ }^{5-7}$ but these analyses comprised poor-quality trials that included patients with variable risk of stress ulcers and assessed different outcomes (overt versus clinically important bleeding). The trials varied in sample size from 28 to 359 patients, and were underpowered relative to the landmark Cook trial ( $n=1200$ patients). Individually, neither the larger trials (with sample sizes ranging from 189 to 359 patients) nor the trials with less bias were able to demonstrate a difference in clinically important bleeding between PPIs and H2RAs. ${ }^{6,7}$ Furthermore, in one of the few positive, yet frequently referenced trials, ${ }^{8}$ the incidence of clinically important bleeding (with endoscopic confirmation of stress ulcers in most patients) was 31\% (11/35) in the H2RA arm, compared with 6\% (2/32) in the PPI arm. This bleeding rate appears unbelievably high relative to the lower rates in all of the other studies, as well as the contemporary estimates of stress ulcers of less than $5 \% .^{9}$ Therefore, the current evidence to support the superiority of PPIs over H2RAs to prevent clinically important bleeding is weak, and the evidence-based standard of practice for stress ulcer prophylaxis should continue to be the use of H2RAs.

There is no doubt that the prevalence of clinically important bleeding from stress ulcers has decreased over time, likely because of improvements in the supportive care of critically ill patients, including prompt and aggressive resuscitation techniques, as well as early institution of enteral feeding. ${ }^{10}$ Although enteral feeding has been associated with a reduction in the risk of clinically important upper gastrointestinal bleeding, ${ }^{11}$ the addition of stress ulcer prophylaxis to enteral feeding has shown variable results in both observational studies and systematic reviews, ranging from no additional benefit ${ }^{12}$ to a lower risk of bleeding relative to enteral feeding alone. ${ }^{11}$ Until data from new prospective trials on the role of enteral nutrition are available, stress ulcer prophylaxis should continue to be a standard of ICU care.

Those who oppose stress ulcer prophylaxis will argue that the risks of acid-suppressive therapy outweigh the benefits. These risks, however, are largely based on the emerging adverse effect profile of the PPIs, including the risks of ventilator-associated pneumonia and Clostridium difficile-associated diarrhea. Observational studies have suggested that increased gastric $\mathrm{pH}$ may be associated with gastric bacterial growth, leading to tracheal colonization, nosocomial pneumonia, and $C$. difficile-associated diarrhea. ${ }^{13,14}$ The risk of ventilator-associated pneumonia, a secondary outcome in the 1998 trial of Cook and others, ${ }^{4}$ was no higher with H2RAs than with sucralfate. In contrast, data comparing PPIs with H2RAs in terms of their association with nosocomial pneumonia are conflicting. Although several metaanalyses comparing PPIs and H2RAs showed no difference in the rate of nosocomial pneumonia, ${ }^{5-7}$ several large observational studies have suggested an increased risk of pneumonia with PPIs relative to H2RAs. ${ }^{15,16}$ Similarly, although observational studies have suggested an association between the use of PPIs and C. difficile-associated diarrhea, ${ }^{14,17}$ the risk of this problem with use of H2RA appears to be lower. ${ }^{16,18}$ Therefore, although risks of stress ulcer prophylaxis do exist with acid-suppressive therapies, these risks may be lower with H2RAs. 
The prospective SUP-ICU trial, ${ }^{19}$ which will randomly assign $3350 \mathrm{ICU}$ patients to receive stress ulcer prophylaxis with a PPI or placebo, should provide answers to some of these questions. The primary objective of this trial will be to compare 90-day mortality, but it will also include assessments of clinically important gastrointestinal bleeding, pneumonia, and $C$. difficile infections. If the results of this study are neutral (similar efficacy for PPI and placebo), stress ulcer prophylaxis with acid-suppressive therapy will likely no longer be routinely used in the ICU. If the results show that PPIs are associated with better survival than is achieved with placebo, there will still be uncertainty with regard to the efficacy and safety of PPIs relative to H2RAs.

Stress ulcer prophylaxis remains the standard of practice for critically ill patients worldwide, ${ }^{20}$ as recommended by international guidelines. ${ }^{21}$ Prophylaxis with H2RAs should continue to be the standard of care until large, prospective, randomized controlled trials demonstrate otherwise. PPIs have not been unequivocally shown to be superior for stress ulcer prophylaxis and may be associated with increased cost and risk relative to H2RAs.

\section{References}

1. Lucas CE, Sugawa C, Riddle J, Rector F, Rosenberg B, Walt AJ. Natural history and surgical dilemma of "stress" gastric bleeding. Arch Surg. 1971; 102(4):266-73.

2. Cook DJ, Griffith LE, Walter SD, Guyatt GH, Meade MO, Heyland DK, et al. The attributable mortality and length of intensive care unit stay of clinically important gastrointestinal bleeding in critically ill patients. Crit Care. 2001;5(6):368-75.

3. American Society of Health-System Pharmacists. ASHP therapeutic guidelines on stress ulcer prophylaxis. Am J Health Syst Pharm. 1999;56(4):347-79.

4. Cook D, Guyatt G, Marshall J, Leasa D, Fuller H, Hall R et al.; Canadian Critical Care Trials Group. A comparison of sucralfate and ranitidine for the prevention of upper gastrointestinal bleeding in patients requiring mechanical ventilation. N Engl J Med. 1998;338(12):791-7.

5. Barkun AN, Bardou M, Pham CQD, Martel M. Proton pump inhibitors vs. histamine 2 receptor antagonist for stress-related mucosal bleeding prophylaxis in critically ill patients: a meta-analysis. Am J Gastroenterol. 2012;107(4):507-20.

6. Alhazzani W, Alenezi F, Jaeschke RZ, Moayyedi P, Cook DJ. Proton pump inhibitors versus histamine 2 receptor antagonists for stress ulcer prophylaxis in critically ill patients: a systematic review and meta-analysis. Crit Care Med. 2013;41(3):693-705.

7. Alshamsi F, Belley-Cote E, Cook D, Almenawer SA, Alqahtani Z, Perri D, et al. Efficacy and safety of proton pump inhibitors for stress ulcer prophylaxis in critically ill patients: a systematic review and meta-analysis of randomized trials. Crit Care. 2016;20(1):120-32.

8. Levy MJ, Seelig CB, Robinson NJ, Ranney JE. Comparison of omeprazole and ranitidine for stress ulcer prophylaxis. Dig Dis Sci. 1997;42(6):1255-9.

9. Krag M, Perner A, Møller MH. Stress ulcer prophylaxis in the intensive care unit. Curr Opin Crit Care. 2016;22(2):186-90.

10. Faisy C, Guerot E, Diehl JL, Iftimovici E, Fagon JY. Clinically significant gastrointestinal bleeding in critically ill patients with or without stress-ulcer prophylaxis. Intensive Care Med. 2003;29(8):1306-13.

11. Cook D, Heyland D, Griffith L, Cook R, Marshall J, Pagliarello J; Canadian Critical Care Trials Group. Risk factors for clinically important upper gastrointestinal bleeding in patients requiring mechanical ventilation. Crit Care Med. 1999;27(12):2812-7.

12. Marik PE, Vasu T, Hirani A, Pachinburavan M. Stress ulcer prophylaxis in the new millennium: a systematic review and meta-analysis. Crit Care Med. 2010;38(11):2222-8.
13. Herzig SJ, Howell MD, Ngo LH, Marcantonio ER. Acid-suppressive medication use and the risk for hospital-acquired pneumonia. JAMA. 2009; 301(20):2120-8.

14. Dial S, Alrasadi K, Manoukian C, Huang A, Menzies D. Risk of Clostridium difficile diarrhea among hospital inpatients prescribed proton pump inhibitors: cohort and case-control studies. CMAJ. 2004;171(1):33-8.

15. Miano TA, Reichert MG, Houle TT, MacGregor DA, Kincaid EH, Bowton DL. Nosocomial pneumonia risk and stress ulcer prophylaxis: a comparison of pantoprazole vs ranitidine in cardiothoracic surgery patients. Chest. 2009;136(2):440-7.

16. MacLaren R, Reynolds PM, Allen RR. Histamine-2 receptor antagonists vs proton pump inhibitors on gastrointestinal tract hemorrhage and infectious complications in the intensive care unit. JAMA Intern Med. 2014;174(4): 564-74.

17. Janarthanan S, Ditah I, Adler DG, Ehrinpreis MN. Clostridium difficileassociated diarrhea and proton pump inhibitor therapy: a meta-analysis. Am J Gastroenterol. 2012;107(7):1001-10.

18. Kwok CS, Arthur AK, Anibueze CI, Singh S, Cavallazi R, Loke YK. Risk of Clostridium difficile infection with acid suppressing drugs and antibiotics: meta-analysis. Am J Gastroenterol. 2012;107(7):1011-9.

19. Krag M, Perner A, Wetterslev J, Wise MP, Borthwick M, Bendel S, et al.; SUP-ICU investigators. Stress ulcer prophylaxis with a proton pump inhibitor versus placebo in critically ill patients (SUP-ICU trial): study protocol for a randomised controlled trial. Trials. 2016;17:205.

20. Krag M, Perner A, Wetterslev J, Wise MP, Borthwick M, Bendel S, et al.; SUP-ICU Collaborators. Stress ulcer prophylaxis in the intensive care unit: an international survey of 97 units in 11 countries. Acta Anaesthesiol Scand. 2015;59(5):576-85.

21. Rhodes A, Evans LE, Alhazzani W, Levy MM, Antonelli M, Ferrer R, et al. Surviving Sepsis Campaign: international guidelines for management of sepsis and septic shock: 2016. Crit Care Med. 2017;45(3):486-552.

Sharon Yamashita, BSCPhm, ACPR, PharmD, FCSHP

Pharmacy Department

Sunnybrook Health Sciences Centre

Toronto, Ontario

Competing interests: None declared.

\section{THE "CON" SIDE}

Much research and many knowledge translation efforts have focused on increasing the incorporation of best available evidence into clinical care. The obverse- de-adopting interventions with little value or with demonstrated harm-is another crucial aspect of improving the care provided in the intensive care unit (ICU). ${ }^{1}$ Why have some practices, such as use of pulmonary catheters and drotrecogin alfa, decreased in the face of evidence of harm or no benefit, ${ }^{2,3}$ while others, such as application of restrictive transfusion thresholds and intensive glucose control, been more difficult to de-adopt ${ }^{24,5}$ The persistence of entrenched practice in the face of opposing evidence is a complex phenomenon, and the social context and historical, economic, and professional forces may be more important than the evidence. ${ }^{67}$ Which practices in critical care are ready for de-adoption? Routine stress ulcer prophylaxis for both critically ill children and adults is an ideal candidate. The current best evidence does not support an effect on patient-important outcomes, and there is indirect evidence that 


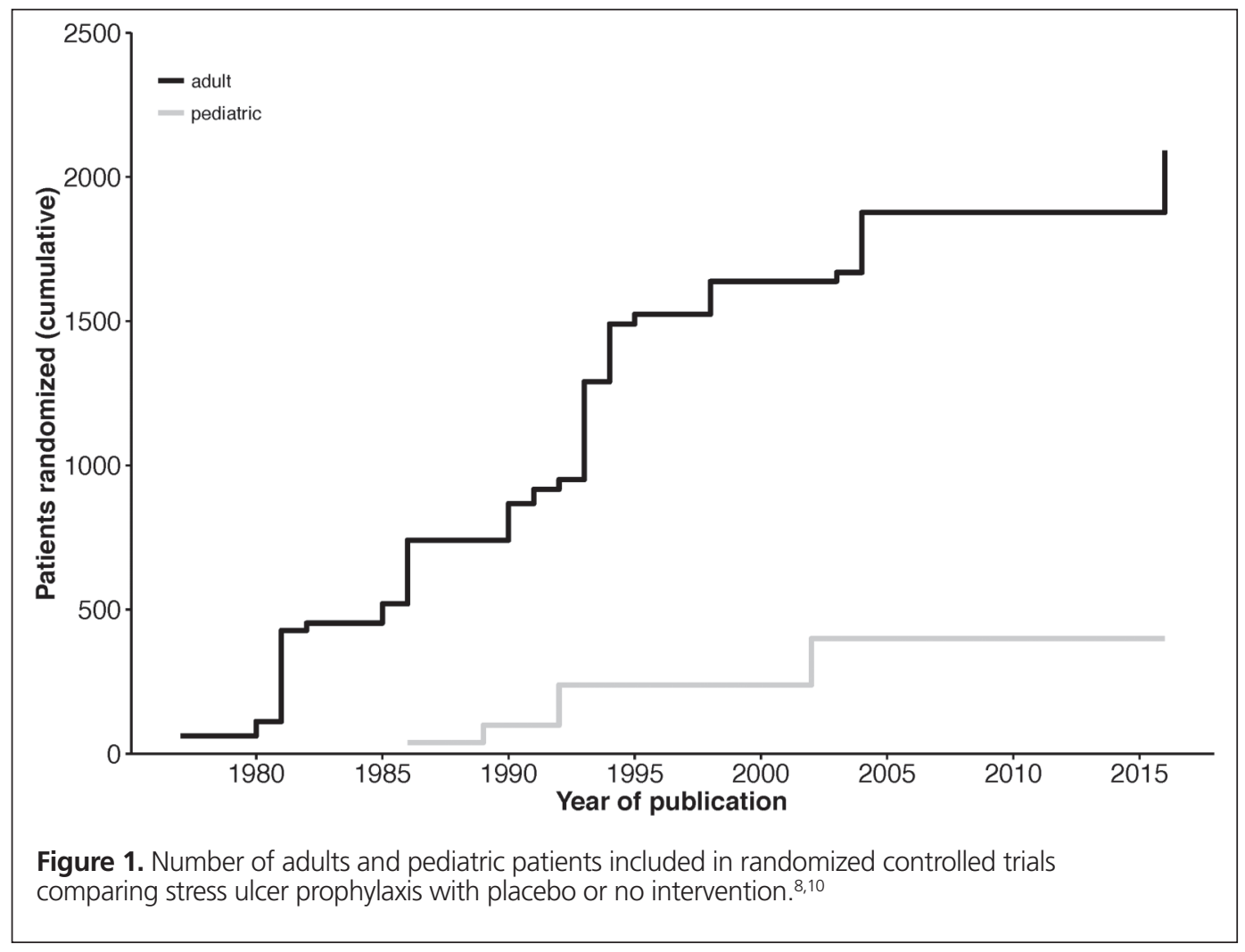

acid suppression is associated with an increased risk of nosocomial infection, primarily ventilator-associated pneumonia and Clostridium difficile-associated diarrhea.

Stress ulcer prophylaxis was a success story in critical care research in the 1980s and 1990s, and became one of the few interventions supported by numerous randomized controlled trials (RCTs). However, many of these trials were small, and all were at high risk of bias. In the 20 published trials involving adults (with randomization of 1971 patients), stress ulcer prophylaxis was associated with reduced gastrointestinal bleeding (relative risk [RR] 0.4, 95\% confidence interval [CI] 0.3-0.7) but not reduced mortality (RR 1.0, 95\% CI 0.8-1.2). ${ }^{8}$ The data for children are even sparser. In 3 trials (with randomization of 340 children), prophylaxis was not associated with a reduction in bleeding (RR 0.7, 95\% CI 0.4-1.2). ${ }^{9}$ Despite no clear effect on mortality or even clinically important bleeding, stress ulcer prophylaxis was incorporated into guidelines and has been widely adopted as a standard practice, based on the association of gastrointestinal bleeding with ICU length of stay and mortality, combined with the perceived benign nature of the intervention. After the initial enthusiasm, though, the research focus shifted to comparing agents, and no RCTs comparing stress ulcer prophylaxis with placebo were published between 2004 and 2016 (Figure 1).

Do the benefits of stress ulcer prophylaxis outweigh the risk of nosocomial infection? Although there is some uncertainty about the magnitude of the benefits of routine stress ulcer prophylaxis, there is even more uncertainty about the magnitude of the harms. In obser- vational studies, acid suppression has been clearly associated with C. difficile-associated diarrhea in critically ill patients (odds ratio [OR] 2.0, 95\% CI 1.2-3.4) $)^{11}$ and with both pneumonia and C. difficile-associated diarrhea in other populations. ${ }^{12,13}$ The RCTs published to date are not sufficient to quantify the risks of stress ulcer prophylaxis. The important limitations of these trials — particularly the definitions of, and surveillance for, pneumonia - and wide CIs substantially reduce the strength of conclusions that can be drawn. Thus, we cannot confidently conclude that stress ulcer prophylaxis does not increase the risk of pneumonia, despite RCT findings for adults (7 trials, 1009 patients; RR 1.2, 95\% CI 0.8-1.6) and children (1 trial; RR 1.1, 95\% CI 0.7-1.8). One RCT involving adults reported the incidence of $C$. difficile-associated diarrhea, but it identified only a single case. ${ }^{10}$

Balancing these risks and benefits is imperative because nosocomial infections are more common in the ICU than is gastrointestinal bleeding. The best estimate of the incidence of gastrointestinal bleeding with modern ICU care-including high use of acid suppression — comes from a prospective observational study that included 1034 patients in 97 ICUs from 11 countries. ${ }^{14}$ Clinically important bleeding occurred in $2.6 \%$ (95\% CI $1.6 \%-3.6 \%$ ) of the patients, but half of these cases occurred within the first 2 ICU days and were unlikely to be prevented by initiation of stress ulcer prophylaxis at the time of ICU admission. In contrast, the incidence of $C$. difficile-associated diarrhea acquired during the ICU stay was $2 \%(95 \%$ CI $1 \%-2 \%)$ in a systematic review of 
22 observational studies involving a total of 80835 ICU patients. ${ }^{15}$ Reported rates of ventilator-associated pneumonia vary widely with the study and definition used, but are likely about 13\% (95\% CI $11 \%-16 \%)$ in adults. ${ }^{16}$

In the absence of compelling evidence of benefit and with uncertainty about the magnitude of the harms, clearly we should de-adopt routine stress ulcer prophylaxis for critically ill children and adults. Evidence is only one factor in successful de-adoption. Why has stress ulcer prophylaxis in particular persisted, and why will it be challenging to de-adopt? I propose 4 specific barriers:

- Stress ulcer prophylaxis has become ingrained in critical care practice: it is included in guidelines and lends itself to protocols and use as a performance measure.

- The adverse effects of the medications used for stress ulcer prophylaxis occur only rarely.

- It is difficult to attribute ventilator-associated pneumonia or C. difficile-associated diarrhea in an individual patient directly to acid suppression. Patients who experience these problems usually have other risk factors, and both conditions can occur in patients who are not receiving acid suppression.

- The medications used for stress ulcer prophylaxis are inexpensive, which reduces the economic forces that may assist de-adoption in other scenarios.

Although the best evidence available today supports the deadoption of routine stress ulcer prophylaxis, uncertainty persists. The quality of the best available evidence for benefit is generally low, and the evidence for harms is largely indirect. RCTs to resolve this uncertainty are under way in both adults ${ }^{17,18}$ and children. ${ }^{19}$ Until the results of these trials allow us to balance the benefits and harms, we should take a cautious approach, challenge entrenched practice, and de-adopt routine stress ulcer prophylaxis in modern critical care. Then, we should shift our focus from preventing infrequent gastrointestinal bleeding of uncertain impact on patient-important outcomes to preventing the more frequent, and perhaps more important, nosocomial infections.

\section{References}

1. Niven DJ, Mrklas KJ, Holodinsky JK, Straus SE, Hemmelgarn BR, Jeffs LP, et al. Towards understanding the de-adoption of low-value clinical practices: a scoping review. BMC Med. 2015;13:255.

2. Kahn JM, Le TQ. Adoption and de-adoption of drotrecogin alfa for severe sepsis in the United States. J Crit Care. 2016;32:114-9.

3. Wiener RS, Welch HG. Trends in the use of the pulmonary artery catheter in the United States, 1993-2004. JAMA. 2007;298(4):423-9.

4. Corwin HL, Gettinger A, Pearl RG, Fink MP, Levy MM, Abraham E, et al. The CRIT Study: anemia and blood transfusion in the critically ill—current clinical practice in the United States. Crit Care Med. 2004;32(1):39-52.

5. Niven DJ, Rubenfeld GD, Kramer AA, Stelfox HT. Effect of published scientific evidence on glycemic control in adult intensive care units. JAMA Intern Med. 2015;175(5):801-9.

6. Prasad V, Ioannidis JP. Evidence-based de-implementation for contradicted, unproven, and aspiring healthcare practices. Implement Sci. 2014;9:1.

7. Montini T, Graham ID. "Entrenched practices and other biases": unpacking the historical, economic, professional, and social resistance to de-implementation. Implement Sci. 2015;10:24.
8. Krag M, Perner A, Wetterslev J, Wise MP, Møller MH. Stress ulcer prophylaxis versus placebo or no prophylaxis in critically ill patients. A systematic review of randomised clinical trials with meta-analysis and trial sequential analysis. Intensive Care Med. 2014;40(1):11-22.

9. Duffett M, Choong K, Foster J, Gilfoyle E, Lacroix J, Randolph A, et al. Stress ulcer prophylaxis in critically ill children: a systematic review [abstract PICC-0055]. In: 8th World Congress on Pediatric Intensive and Critical Care; 2016 June 4-8; Toronto (ON). Available from: www.picc2016.com/ PublishingImages/scientific-information-abstracts/scientific-program/ PICC\%202016\%20posters\%20abstracts\%20all.pdf

10. Selvanderan SP, Summers MJ, Finnis ME, Plummer MP, Ali Abdelhamid Y, Anderson MB, et al. Pantoprazole or placebo for stress ulcer prophylaxis (POP-UP): randomized double-blind exploratory study. Crit Care Med. 2016;44(10):1842-50.

11. Barletta JF, Sclar DA. Proton pump inhibitors increase the risk for hospitalacquired Clostridium difficile infection in critically ill patients. Crit Care. 2014;18(6):714.

12. Lambert AA, Lam JO, Paik JJ, Ugarte-Gil C, Drummond MB, Crowell TA. Risk of community-acquired pneumonia with outpatient proton-pump inhibitor therapy: a systematic review and meta-analysis. PLoS One. 2015; 10(6):e0128004.

13. Leonard J, Marshall JK, Moayyedi P. Systematic review of the risk of enteric infection in patients taking acid suppression. Am J Gastroenterol. 2007; 102(9):2047-56

14. Krag M, Perner A, Wetterslev J, Wise MP, Borthwick M, Bendel S, et al. Prevalence and outcome of gastrointestinal bleeding and use of acid suppressants in acutely ill adult intensive care patients. Intensive Care Med. 2015;41(5):833-45.

15. Karanika S, Paudel S, Zervou FN, Grigoras C, Zacharioudakis IM, Mylonakis E. Prevalence and clinical outcomes of Clostridium difficile infection in the intensive care unit: a systematic review and meta-analysis. Open Forum Infect Dis. 2016;3(1):ofv186.

16. Muscedere J, SinuffT, Heyland DK, Dodek PM, Keenan SP, Wood G, et al. The clinical impact and preventability of ventilator-associated conditions in critically ill patients who are mechanically ventilated. Chest. 2013;144(5): 1453-60.

17. McMaster University. Re-evaluating the inhibition of stress erosions: gastrointestinal bleeding prophylaxis in ICU (REVISE) [trial registration]. ClinicalTrials.gov identifier NCT02290327. Bethesda (MD): National Institutes of Health; 2014 Oct 31 [updated 2016 Feb 5; cited 2017 Jul 4]. Available from: https://clinicaltrials.gov/ct2/show/NCT02290327

18. Møller MH. Stress ulcer prophylaxis in the intensive care unit (SUP-ICU) [trial registration]. ClinicalTrials.gov identifier NCT02467621. Bethesda (MD): National Institutes of Health; 2015 Jun 5 [updated 2017 Apr 27; cited 2017 Jul 4]. Available from: https://clinicaltrials.gov/ct2/show/ NCT02467621

19. McMaster University. Pediatric intensive care ulcer prophylaxis pilot trial (PIC-UP) [trial registration]. ClinicalTrials.gov identifier NCT02929563. Bethesda (MD): National Institutes of Health; 2016 Oct 3 [updated 2017 May 15; cited 2017 Jul 4]. Available from: https://clinicaltrials.gov/ct2/ show/NCT02929563

Mark Duffett, PhD, RPh

Pediatric Critical Care

McMaster Children's Hospital

McMaster University Medical Centre

Hamilton, Ontario

Mark Duffett is a coauthor on a paper published in this issue of the Canadian Journal of Hospital Pharmacy, reporting results of a survey about the need for a trial of pediatric stress ulcer propyhlaxis; see page 288.

Competing interests: None declared. 